\title{
Effect of Telecollaboration on Translation of Culture-Bound Texts
}

\author{
Vahid Rafieyan \\ International College of Liberal Arts, Yamanashi Gakuin University, Kofu, Yamanashi, Japan \\ E-mail: rafieyanv@ygu.ac.jp
}

Received: 28-02-2016

Published: 01-07-2016
Accepted: 01-05-2016

doi:10.7575/aiac.ijalel.v.5n.4p.127
Advance Access Published: May 2016

URL: http://dx.doi.org/10.7575/aiac.ijalel.v.5n.4p.127

\begin{abstract}
One of the most problematic perspectives of translation phenomenon is the cultural gap between the source language and the target language (Yang, 2010). This gap can be ideally filled through telecollaboration which provides internationally dispersed language learners in parallel language classes with cost-effective access to, and engagement with, peers who are expert speakers of the language under study (Belz, 2005). To investigate the effect of telecollaboration on the quality of translation of culture-bound texts, the current study was conducted on 64 Iranian undergraduate students of English translation at a university in Iran. Instruments used in the study consisted of three texts containing news excerpts from Voice of America (VOA). The study consisted of three phases: 1) assessing quality of translation of culture-bound texts, 2) random assignment of participants to two groups: one merely receiving cultural instruction while the other being linked to native English speakers through LinkedIn alongside receiving cultural instruction, and 3) assessing quality of translation of culture-bound texts immediately and two months following treatment. The results of mixed between-within subjects analysis of variance revealed the significant positive effect of telecollaboration on developing quality of translation of culture-bound texts and sustaining the attained knowledge. The pedagogical implications of the findings suggested incorporation of cultural components of source language society into translation courses and providing opportunities for translation students to be exposed to authentic and intensive source language culture through telecollaboration.
\end{abstract}

Keywords: Culture-Bound Texts, Cultural instruction, Telecollaboration, Translation

\section{Introduction}

A language reflects the cultural perspectives of the speakers of that language. Therefore, translation can be considered a linguistic filter for cross-cultural comparison in which languages, societies, and cultures are being compared (Paniagua, 2000). Since translating from one language into another language is comparing the cultures of the speakers of both languages (Nord, 2001) and language comes out of social interactions and is embedded in a sociolinguistic and sociocultural context, familiarity with this context is important in order to be able to decode messages appropriately (Albirini, 2009). Therefore, cultural values of the source language society and their target language equivalents ought to be considered in translation activities and translators ought to be able to prioritize the social perspectives in their work (Toury, 1995). In order for the source and the target language audiences to be able to experience the same conditions, the translator should have the ability of noticing any inter-textual component and render them equivalently into the target language. This is possible only when the translator possesses the required cultural background knowledge (Agost, 1998). These textual components carry signs which need to be interpreted in order to be fully comprehensible for the receiver; therefore, translator needs to dominate the sociolinguistic and sociocultural perspectives of the source language (Agost, 1999). Domination of sociolinguistic and sociocultural perspectives of the source language can be best achieved through exposure to source language culture and contact with source language speakers. Language learners in the second language context are exposed to the sociolinguistic and sociocultural features of the source language community to a great extent and as a result have a lot of opportunities to apply those sociolinguistic and sociocultural features in their everyday interactions. However, language learners in a foreign language context are deprived from exposure to the sociolinguistic and sociocultural features of the source language community in order to develop their intercultural competence (Martinez-Flor, 2008; Neddar, 2012; Khodareza \& Lotfi, 2012). Such an intercultural contact can be conveniently facilitated through the provision of opportunities for foreign language learners to engage in computer-mediated intercultural communication with source language speakers using technological tools such as synchronous chat and e-mail as well as popular social networks such as Facebook, Skype, LinkedIn, and WhatsApp through an approach referred to as "telecollaboration". Telecollaboration, defined as "institutionalized, electronically mediated intercultural communication under the guidance of a languacultural expert (i.e., a teacher) for the purposes of foreign language learning and the development of intercultural competence" (Belz, 2003, p. 2), involves the application of global computer networks to foreign language learning in institutionalized setting. In telecollaborative partnership, internationally dispersed language learners in parallel language classes are provided with cost-effective access to, and engagement with, peers who are expert speakers of the language under study (Belz, 2005). 
The effect of telecollaborative partnership on the development of language learners' sociolinguistic and sociocultural aspects of the language to be learned has been investigated in a number of studies. In one of these studies, Kinginger and Belz (2005) examined the effect of telecollaborative partnership on the development of a particular feature of pragmatic competence namely address form competence in German. The study was conducted on an English-speaking learner of German in the United States who participated for an eight-week period in an electronically mediated partnership with expert speakers of German through an Internet-mediated class-to-class pedagogical exchange. A corpus-assisted microgenetic approach characterized as "the observation of skill acquisition during a learning event" (Belz \& Kinginger, 2003, p. 594) with a longitudinal scope was adopted to examine the telecollaborative classroom. The study revealed the language learner's development pathway toward expertise in the use of the address form system. In another study, Vyatkina and Belz (2006) employed the twin research methodologies of contrastive learner corpus analysis and microgenesis in the context of telecollaborative language and culture learning partnerships to examine the emergence of a critical feature of pragmatic competence namely the comprehension and production of modal particles in German. The participants in the study consisted of a group of American learners of German at a university in the United States and their German key-pals enrolled at a college in Germany. Telecollaborative native speaker/nonnative speaker correspondence continued for a 9-week period through e-mail and synchronous chat. The findings of the study showed that the telecollaborative partnership was effective in the development of comprehension and production of modal particles. Cunningham and Vyatkina (2012) also conducted a study to investigate whether interaction with expert users of German combined with a data-driven instructional intervention improve German learners' use of politeness strategies. The participants in their study consisted of a group of American learners of German at a university in the United States. The instructional context of the study was a telecollaborative web conferencing exchange between learners of German and German professionals. The study employed the method of microgenetic analysis. The study revealed that telecollaborative partnership was effective in the development of pragmatic competence. Rafieyan et al. (2014) were the other researchers who investigated the role of telecollaborative partnership in developing language learners' level of pragmatic comprehension. Participants in the study consisted of two groups of undergraduate students of English at a university in Iran: a control group receiving pragmatic instruction and an experimental group being paired with American peers through Facebook alongside receiving pragmatic instruction. Data were collected through a multiple choice pragmatic comprehension test following a semester-long intervention. The study revealed the significant positive effect of telecollaborative partnership on the development of pragmatic comprehension. Most recently, Rafieyan et al. (2015) explored the effect of developing pragmatic competence through telecollaboration on improving English as foreign language learners' writing proficiency. Participants of the study consisted of two groups of advanced-level learners of English at a Company in Iran: a control group being instructed on letter writing strategies and an experimental group being linked to native English speakers through a WhatsApp group alongside instruction on letter writing strategies. To collect data, participants were sought to write three letters of application in response to job advertisements: one before treatment, one after an eight-session treatment, and the other one two months following the treatment. The study revealed that developing target language pragmatic competence through telecollaboration has a significantly positive impact on improving target language writing proficiency and maintaining the obtained knowledge to a great extent.

The studies conducted so far have investigated the effect of developing sociolinguistic and sociocultural knowledge in language learners through telecollaboration on the development of their linguistic and pragmatic competence. However, considering the significance of possessing the sociolinguistic and sociocultural knowledge of source language in ideal transference of meaning of source language into target language on one hand and the significant effect of telecollaboration on the development of sociolinguistic and sociocultural knowledge of source language on the other hand, the current study seeks to investigate the effect of developing source language sociolinguistic and sociocultural knowledge through telecollaboration on the quality of translation of culture-bound texts. Therefore, the research question to be addressed in the current study is:

To what extent does telecollaboration affect the quality of translation of culture-bound texts?

Accordingly the null hypothesis is:

Telecollaboration has no effect on the quality of translation of culture-bound texts.

\section{Methodology}

\subsection{Participants}

Participants of the study consisted of 64 Iranian undergraduate students of English translation at a university in Iran. They were all at the last semester of their studies and had passed the majority of translation courses; thus, they were supposed to possess a good command of English translation. The participants' ages ranged from 22 to 28 with a mean age of 24.2. Among all the participants, 26 were males and 38 were females. None of the participants had previously visited or lived in an English speaking country nor had contact with native English speakers; therefore, they have not had the opportunity to be exposed to target language culture or have contact with target language speakers to develop their intercultural competence, that is, their "complex of abilities needed to perform effectively and appropriately when interacting with others who are linguistically and culturally different from oneself" (Fantini 2006: 12).

Alongside the Iranian participants, 12 American undergraduate students of cultural studies at a university in the United States participated in the study. The American participants were linked to Iranian students through a LinkedIn group created and moderated by the researcher to provide a virtual environment for both groups of participants (Iranians and 
Americans) to interact with each other and exchange cultural knowledge of their countries. These participants volunteered to participate in order to expand their cultural knowledge of Iran as they were studying about or interested in Persian culture. This could for sure positively influence the consistency of contact and cultural correspondence between the two groups of participants. However, this participant group was merely used to provide telecollaborative partnership and was not included in the translation quality assessment and analysis of the study.

\subsection{Instruments}

The instruments used to collect data consisted of three texts flooded with cultural features of the United States. The texts contained some excerpts of news adopted from Voice of America (VOA) which is the official external broadcast institution of the United States federal government. The criterion for the selection of the news excerpts for each text was the inclusion of a large quantity of cultural features of the United States. The researcher carefully reviewed current news on VOA website and selected excerpts which contained abundant cultural features of the United States. Moreover, to ensure that the translators do their best to present a translation to the best of their knowledge, the texts were kept within a page limit (within 325-375 words) to avoid making the translation task tedious. Also, to make sure that all three texts have the same level of difficulty, they were roughly kept at the same length and number of American cultural references.

To assess the validity of the culture-bound texts, content-related evidence of validity was used. The researcher wrote out the definition of what he wanted to measure and then gave this definition, along with the culture-bound texts and a description of the intended sample, to two professors at a university in Iran who were experts in the field of translation. The professors confirmed that the content and format is consistent with the definition of the variable and the sample of objects to be measured (Fraenkel et al., 2012). To assess the reliability of the culture-bound texts, a pilot study was conducted over 30 nonparticipant senior Iranian undergraduate students of translation at a university in Iran. The reliability coefficient of the culture-bound texts used as pre-test, post-test, and follow-up test assessed through Cronbach's alpha were respectively $0.80,0.85$, and 0.82 .

\subsection{Procedure}

At the beginning of the fall semester in academic year 2015/2016, the culture-bound text used as pre-test was administered to all Iranian participants to be translated. They were then randomly assigned to two equal groups: a control group (32 participants) and an experimental group (32 participants). Cultural features of the United States were incorporated into the regular classes for both groups of participants but participants in the experimental group had the added opportunity of being linked to American students through a LinkedIn group. The group was moderated by the researcher to make sure all students are actively involved in interaction and exchanging cultural knowledge with their American peers through guided topics. The topics covered a variety of cultural features such as holidays, festivals, foods, greetings, thanking, refusing, apologizing, and so on. The cultural instruction and group activity was conducted for the whole semester. At the end of the semester, the other culture-bound text used as post-test was administered to all Iranian participants in both groups to be translated. To assess the sustainability of the obtained cultural knowledge, students were asked to translate the other culture-bound text used as follow-up test two months following the semester.

\subsection{Data Analysis}

To assess the performance of translation students, the same professors of translation who judged the validity of culturebound texts for the study rated the quality of translated works on a continuum ranging of 0 to 10 , where 0 represented the worst and 10 represented the best quality of translation. Quality of translations was assessed based on House's (1977, 1997) functional-pragmatic model which consisted of three steps: (1) the source text was analyzed along the dimensions of Field, Tenor, and Mode. On the basis of findings on the lexical, the syntactic, and the textual level, a text-profile was set up which reflected the individual textual function; (2) the translated text was analyzed along the same dimensions and at the same level of delicacy; (3) the source and translation texts were compared. An assessment of their relative match was established: how the two texts were similar and/or different, given differing linguistic and cultural constraints (Thuy, 2013).

To measure the level of agreement between the ratings assigned by the two raters, the inter-rater reliability was assessed through Cohen's Kappa which is a measure of inter-rater reliability used to measure agreement between two coders (Saldanha \& O'Brien, 2014). The analysis of Cohen's Kappa would give a value between -1 and +1 . Landis and Koch (1977) have set a series of guidelines to interpret the values obtained through Cohen's Kappa. According to Landis and Koch (1977), values smaller than 0.00 indicate poor agreement, values between 0.00 and 0.20 indicate slight agreement, values between 0.21 and 0.40 indicate fair agreement, values between 0.41 and 0.60 indicate moderate agreement, values between 0.61 and 0.80 indicate substantial agreement, and values between 0.81 and 1.00 indicate an almost perfect agreement between the two raters. The inter-rater reliability assessed for the translations was 0.85 , which according to the guidelines set by Landis and Koch (1977), indicates an almost perfect agreement between the two raters. For cases which received different ratings, the raters discussed until they reached an agreement.

To assess the effect of telecollaboration on quality of translation of culture-bound texts, mixed between-within subjects analysis of variance, which allows combining between-subjects and within-subjects variables in one analysis (Pallant, 2013), was performed over the ratings assigned to the translations of culture-bound texts used as pre-test, post-test, and follow-up test for the two groups (control group and experimental group). In this respect, both the general effect of intervention as a whole (within-subjects effect) and the effect of specific type of intervention, that is, inclusion of cultural instruction along with telecollaboration versus inclusion of cultural instruction without telecollaboration (between-subjects effect) was considered. Partial eta squared was then used to examine the level of effect of 
intervention for both within-subjects and between-subjects categories. Partial eta squared can range from 0 to 1 and represents the proportion of variance in the dependent variable (quality of translation of culture-bound texts) that is explained by the independent variable (type of treatment) (Pallant, 2013). Cohen (1988) proposed a set of guidelines to interpret the values of partial eta squared. According to Cohen (1988), a value of 0.01 indicates small effect, a value of 0.06 indicates moderate effect, and a value of 0.14 indicates large effect. Finally, the graphical presentation of the performance of participants in both control and experimental groups on the translation of culture-bound texts used as pre-test, post-test, and follow-up test was provided.

\section{Results}

Table 1 presents the results of the descriptive analysis of the data. The descriptive analysis presented in the table consists of the number of participants in each group as well as the mean and standard deviation obtained for the performance of each group of participants on pre-test, post-test, and follow-up test. According to the descriptive analysis of the data, although the mean score for the performance of translation students in both control and experimental groups on the translation of culture-bound text enhanced in post-test and follow-up test, the mean score obtained by translation students in the experimental group was higher than the mean score obtained by translation students in the control group. The mean score by itself, however, does not show whether the difference among the three tests and between the two groups is considered significant or not. To determine whether the difference among mean scores obtained by each group over the three tests is significantly different from one another or not, the results of the analysis of mixed between-within subjects analysis of variance need to be examined.

Table 1. Descriptive Analysis of Data

\begin{tabular}{llccc}
\hline & Group of Participants & Number & Mean & Std. Deviation \\
\hline \multirow{2}{*}{ Pre-test } & control & 32 & 3.44 & 1.190 \\
\cline { 2 - 5 } & experimental & 32 & 3.50 & 1.191 \\
\cline { 2 - 5 } & Total & 64 & 3.47 & 1.181 \\
\hline \multirow{2}{*}{ Post-test } & control & 32 & 5.37 & 1.718 \\
\cline { 2 - 5 } & experimental & 32 & 7.06 & 1.501 \\
\cline { 2 - 5 } & Total & 64 & 6.22 & 1.812 \\
\hline \multirow{2}{*}{ Follow-up Test } & control & 32 & 5.41 & 1.480 \\
\cline { 2 - 5 } & experimental & 32 & 6.06 & 1.849 \\
\cline { 2 - 5 } & Total & 64 & 6.23 & \\
\hline
\end{tabular}

Table 2 presents the results of the main effect for within-subjects variable (time: pre-test, post-test, follow-up test). To explore the main effect for within-subjects variable, the value of Wilks' Lambda and the associated probability value given in the column labeled Significance (Sig.) needs to be considered. All of the multivariate tests yield the same result; however, the most commonly reported statistic is Wilks' Lambda (Pallant, 2013). A significance value of above 0.05 $(\mathrm{p}>0.05)$ for Wilks' Lambda indicates a non-significant effect whereas a significance value of equal or less than 0.05 ( $p$ $\leq 0.05$ ) is indicative of a significant effect (Gravetter \& Wallnau, 2013). In the data obtained in the current study, the value for Wilks' Lambda for time is 0.065 , with a significance value of 0.000 (which really means $\mathrm{p}<0.0005$ ). Because the $\mathrm{p}$ value is less than 0.05 , there is a statistically significant effect for time. This suggests that there was a change in translation quality across the three different time periods. The main effect for time was significant.

Although a statistically significant difference among the performance of translation students on different time intervals (pre-test, post-test, and follow-up test) was found, the effect size of this result also needs to be considered to be able to determine the exact size of this difference. In this regard, the value of interest is partial eta squared. The value of partial eta squared obtained for time in this study is 0.935. Using the commonly used guidelines proposed by Cohen (1988), this result suggests an extremely large effect size. Expressed as a percentage, 93.5 percent of variance in the performance of translation students on the quality of translation of culture-bound texts is explained by the treatment they received at different time intervals.

Table 2. Multivariate Tests ${ }^{\mathrm{a}}$

\begin{tabular}{|c|c|c|c|c|c|c|c|c|}
\hline Effect & & & Value & $\mathrm{F}$ & $\begin{array}{c}\text { Hypothesis } \\
\text { df }\end{array}$ & Error df & Sig. & $\begin{array}{c}\text { Partial Eta } \\
\text { Squared }\end{array}$ \\
\hline \multirow{4}{*}{\multicolumn{2}{|c|}{ Time }} & Pillai's Trace & 0.935 & $439.241^{b}$ & 2.000 & 61.000 & 0.000 & 0.935 \\
\hline & & Wilks' Lambda & 0.065 & $439.241^{b}$ & 2.000 & 61.000 & 0.000 & 0.935 \\
\hline & & Hotelling's Trace & 14.401 & $439.241^{\mathrm{b}}$ & 2.000 & 61.000 & 0.000 & 0.935 \\
\hline & & Roy's Largest Root & 14.401 & $439.241^{b}$ & 2.000 & 61.000 & 0.000 & 0.935 \\
\hline \multirow{4}{*}{$\begin{array}{l}\text { Time } \\
\text { Group }\end{array}$} & $*$ & Pillai's Trace & 0.556 & $38.192^{\mathrm{b}}$ & 2.000 & 61.000 & 0.000 & 0.556 \\
\hline & & Wilks' Lambda & 0.444 & $38.192^{b}$ & 2.000 & 61.000 & 0.000 & 0.556 \\
\hline & & Hotelling's Trace & 1.252 & $38.192^{\mathrm{b}}$ & 2.000 & 61.000 & 0.000 & 0.556 \\
\hline & & Roy's Largest Root & 1.252 & $38.192^{b}$ & 2.000 & 61.000 & 0.000 & 0.556 \\
\hline \multicolumn{9}{|c|}{$\begin{array}{l}\text { a. Design: Intercept + Group } \\
\text { Within Subjects Design: Time } \\
\text { b. Exact statistic }\end{array}$} \\
\hline
\end{tabular}


Now that the within-subjects effects have been explored, the main effect for between-subjects variable (type of intervention: cultural instruction along with telecollaboration versus cultural instruction without telecollaboration) needs to be considered. The results that need to be considered are in Table 3. In this respect, the significance value across the row labeled Group (variable name for the type of intervention) should be considered. A significance value of above 0.05 $(p>0.05)$ for Group indicates a non-significant effect whereas a significance value of equal to or less than 0.05 ( $\mathrm{p} \leq$ 0.05) is indicative of a significant effect (Gravetter \& Wallnau, 2013). In the data obtained in the current study, the significance value for Group is 0.003 . This is less than the alpha level of 0.05 , so the main effect for Group is significant. There was a significant difference in the translation quality for the two groups (those who were electronically linked to American Students and those who were not electronically linked to American Students).

Although a statistically significant difference between the performance of translation students in the two groups (control group and experimental group) was found, the effect size of this result also needs to be considered to be able to determine the exact size of this difference. In this regard, the value of interest is again partial eta squared. The value of partial eta squared obtained for group in this study is 0.136 which, according to the guidelines proposed by Cohen (1988), indicates a large effect size. Expressed as a percentage, 13.6 percent of variance in the performance of translation students on the quality of translation of culture-bound texts is explained by the type of treatment they received.

Table 3. Tests of Between-Subjects Effects

\begin{tabular}{lcccccc}
\hline Source & $\begin{array}{c}\text { Type III Sum } \\
\text { of Squares }\end{array}$ & df & Mean Square & F & Sig. & $\begin{array}{c}\text { Partial Eta } \\
\text { Squared }\end{array}$ \\
\hline Intercept & 5408.130 & 1 & 5408.130 & 853.214 & 0.000 & 0.932 \\
\hline Group & 61.880 & 1 & 61.880 & 9.763 & 0.003 & 0.136 \\
\hline Error & 392.990 & 62 & 6.339 & & & \\
\hline
\end{tabular}

The graphical presentation of the performance of translation students in both control and experimental groups on translating culture-bound texts used as pre-test, post-test, and follow-up test has been depicted in Figure 1. As Figure 1 shows, translation students in both groups exhibited a significant improvement in the quality of translation of culturebound text following a semester-long cultural intervention and maintained the obtained knowledge after two months following the intervention. However, translation students in the experimental group (those who received cultural instruction alongside telecollaboration) exhibited a significantly better improvement than translation students in the control group (those who receied cultural instruction without telecollaboration).

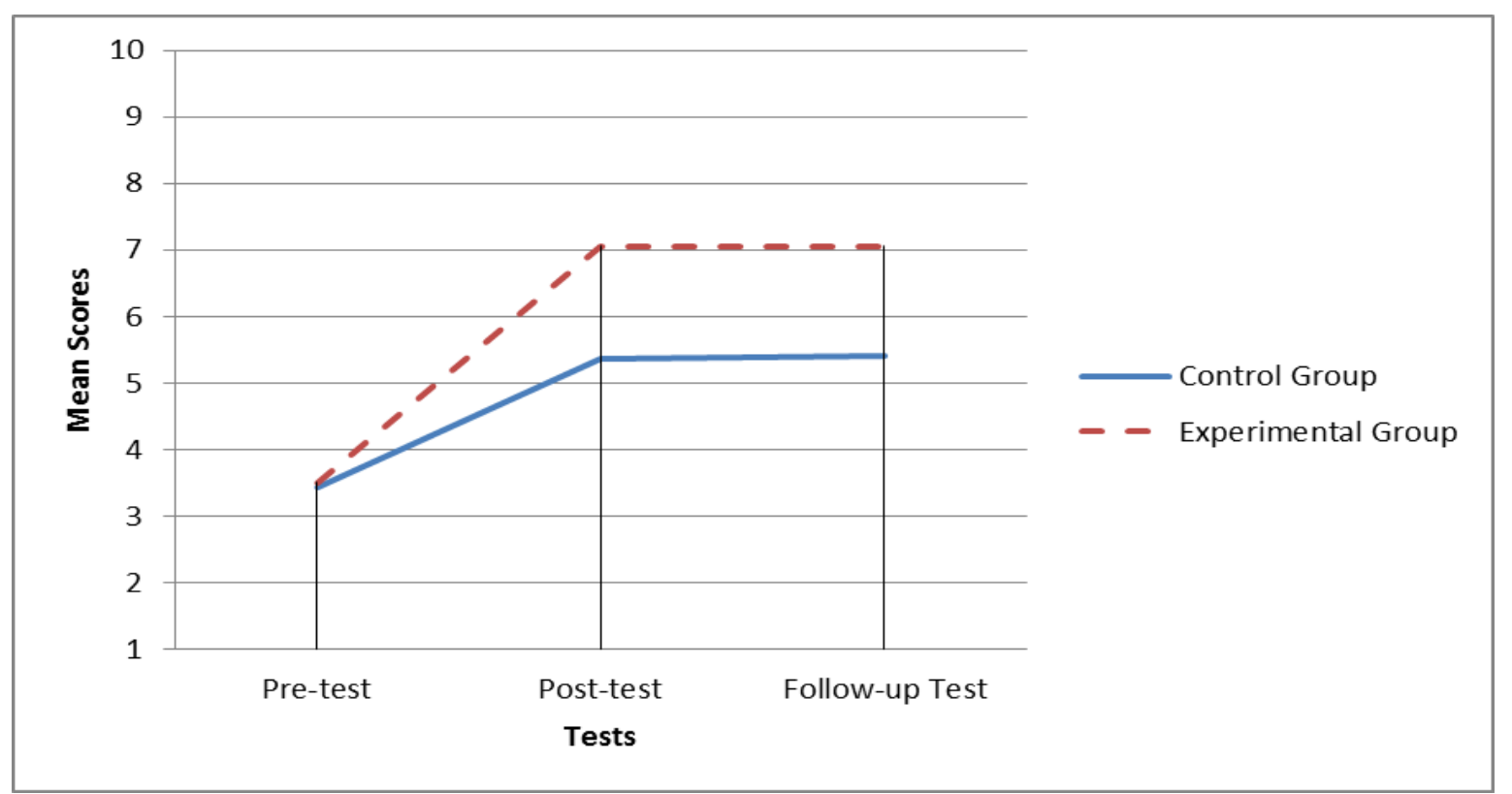

Figure 1. Performance of Participants in Control and Experimental Groups on Pre-test, Post-test, and Follow-up Test

\section{Discussion}

The study found that exposure to source language culture and contact with source language speakers through telecollaboration has a significant positive effect on developing and sustaining quality of translation of culture-bound texts. Students of translation in both control group and experimental group improved the quality of their translation of culture-bound texts following the intervention and managed to maintain the gained ability even after a period of time following intervention. However, students of translation who were linked to source language speakers through LinkedIn 
presented a significantly better quality of translation than those who did not have the opportunity to interact with source language speakers. Therefore, the hypothesis of the study which states telecollaboration has no effect on the quality of translation of culture-bound texts is rejected.

The improvement of quality of translation of culture-bound texts for both groups of participants (those who were in contact with source language speakers through telecollaborative partnership and those who were not involved in telecollaborative partnership) can be attributed to the provision of abundant exposure to source language cultural features. In the current study, translation courses for both groups of participants were furnished with the sociolinguistic and sociocultural features of the source language society and the significance of knowledge of source language sociolinguistic and sociocultural features to render an ideal translation according to the cultural rules of the target language. Furthermore, in the current era, media and social networks have provided exposure to the cultural features of various countries. The awareness of the importance of cultural knowledge in quality of translations developed through cultural instruction has certainly led the attention of translation students participating in the study toward noticing the abundant cultural features they are exposed to and consequently providing them with the opportunities to experience even more cultural gains outside the class. The exposure to this abundant source language cultural input both inside class and outside class environments has definitely helped to develop intercultural competence and the consequent translation ability of culture-bound texts in all translation students participating in the study.

The superior performance of translation students who were involved in telecollaborative partnership with source language speakers (experimental group) on translation of culture-bound text than translation students who were not involved in telecollaborative partnership with source language speakers (control group) can be attributed to the fact that they had more opportunities to be exposed to the sociolinguistic and sociocultural features of the source language and to have contact with source language speakers. Not only had telecollaborative partnership enhanced the awareness of the differences between the sociolinguistic and sociocultural features of the source and target language societies which could affect translation quality in translation students in the experimental group to a greater extent than translation students in the control group but also telecollaborative partnership led them gain more knowledge of ideal transference of cultural references of the source language into the target language. This awareness and knowledge could not be developed in such an extent in translation students who were not involved in telecollaborative partnership as they were not intensely involved in sociolinguistic and sociocultural interactions with source language speakers.

The findings obtained in the current study are in line with the findings obtained in the studies conducted by Kinginger and Belz (2005), Vyatkina and Belz (2006), Cunningham and Vyatkina (2012), and Rafieyan et al. (2014) who found that telecollaboration has a significant effect in the development of pragmatic competence in language learners. The findings obtained in the current study are also consistent with the findings obtained by Rafieyan et al. (2015) who found that telecollaboration has a significantly positive impact on improving target language writing proficiency and maintaining the obtained knowledge to a great extent.

\section{Conclusion}

The study revealed the significant positive effect of telecollaboration on developing quality of translation of culturebound texts and sustaining the attained knowledge. Although cultural treatment developed translation quality for all translation students participating in the study, the gains were greater for those who were involved in telecollaborative partnership with source language speakers than those who were not involved in telecollaborative partnership. Therefore, not only cultural components of source language society should be incorporated in translation courses to help translation students develop intercultural competence (Elyildirim, 2008; Rafieyan et al., 2013a; Rafieyan et al., 2013b; Rafieyan, in press a; Rafieyan, in press b; Rafieyan, in press c) but also translation students should be provided with opportunities to be exposed to authentic and intensive source language sociolinguistic and sociocultural features through telecollaboration.

The study, however, was limited in the way that it did not consider the role of individual differences variables such as attitude toward cultural instruction, cultural intelligence, and cultural distance in the level of cultural knowledge obtained through telecollaborative partnership. Translation students who are more interested in learning the sociolinguistic and sociocultural features of the source language, have a high level of cultural intelligence to quickly learn cultural knowledge they are exposed to, and have a closer distance with source language culture and consequently share abundant cultural features with source language society could have obtained more cultural knowledge through telecollaboration. Therefore, future research is recommended to consider the effect of such individual differences variables as attitude toward cultural instruction, cultural intelligence, and cultural distance from the source language culture on the cultural knowledge obtained through telecollaboration.

\section{Acknowledgements}

The author would like to acknowledge the contribution of Navid Rafieyan.

\section{References}

Agost, R. (1998). Traducció i Intertextualitat: el Cas del Doblatge. In L. Meseguer \& M. L. Villanueva (Eds.), Intertextualitat Irecepció (pp. 219-243). Castellón de la Plana: Universitat Jaume I.

Agost, R. (1999). Traducción y Doblaje: Palabras, Voces e Imágenes. Barcelona: Ariel. 
Albirini, A. (2009). Using Technology, Literature and Guest Speakers to Raise the Cultural Awareness of Arabic Language Learners. The International Journal of Language Society and Culture, 28, 1-15.

Belz, J. A. (2003). From the Special Issue Editor. Language Learning \& Technology, 7(2), 2-5.

Belz, J. A. (2005). Telecollaborative Foreign Language Study: A Personal Overview of Praxis and Research. In D. Hiple, \& I. Thompson (Eds.), Proceedings of the Symposium on Foreign Language Distance Education and Distributed Learning. Honolulu: National Foreign Language Resource Center, University of Hawaii.

Belz, J. A., \& Kinginger, C. (2003). Discourse Options and the Development of Pragmatic Competence by Classroom Learners of German: The Case of Address Forms. Language Learning, 53(4), 591-647. http://dx.doi.org/10.1046/j.1467-9922.2003.00238.x

Cohen, J. (1988). Statistical Power Analysis for the Behavioral Sciences. Hillsdale, NJ: Lawrence Erlbaum Associates.

Cunningham, D. J., \& Vyatkina, N. (2012). Telecollaboration for Professional Purposes: Towards Developing a Formal Register in the Foreign Language Classroom. The Canadian Modern Language Review, 68(4), 422-450. http://dx.doi.org/10.3138/cmlr.1279

Elyildirim, S. (2008). The Importance of Cultural Knowledge in Translation: A Partial Replication of Olk (2003). Sosyal Bilimler Dergisi, 17, 131-144.

Fantini, A. E. (2006). Exploring and Assessing Intercultural Competence. Retrieved 15 February 2012, from http://www.sit.edu/publications/docs/feil_research_report.pdf

Fraenkel, J. R., Wallen, N. E., \& Hyun, H. H. (2012). How to Design and Evaluate Research in Education (8th ed.). New York: McGraw-Hill.

Gravetter, F. J., \& Wallnau, L. B. (2013). Statistics for the Behavioral Sciences (9th ed.). Belmont, C A: Wadsworth Publishing.

House, J. (1977). A Model for Translation Quality Assessment. Tubingen: Narr.

House, J. (1997). Translation Quality Assessment: A Model Revisited. Tubingen: Narr.

Khodareza, M., \& Lotfi, A. R. (2012). Interlanguage Pragmatics Development: Iranian EFL Learners' Interpretation and Use of Speech Acts. Journal of Basic and Applied Scientific Research, 2(9), 9235-9243.

Kinginger, C., \& Belz, J. A. (2005). Socio-Cultural Perspectives on Pragmatic Development in Foreign Language Learning: Microgenetic Case Studies from Telecollaboration and Residence Abroad. Intercultural Pragmatics, 2(4), 369-421. http://dx.doi.org/10.1515/iprg.2005.2.4.369

Landis, J. R., \& Koch, G. G. (1977). The Measurement of Observer Agreement for Categorical Data. Biometrics, 33(1), 159-174. http://dx.doi.org/10.2307/2529310

Martinez-Flor, A. (2008). The Effects of an Inductive-Deductive Teaching Approach to Develop Learners' Use of Request Modifiers in the EFL Classroom. In E. Alcon-Soler (Ed.), Learning How to Request in an Instructed Language Learning Context (pp. 191-225). Bern: Peter Lang.

Neddar, B. A. (2012). Short Notes on Discourse, Interlanguage Pragmatics and EFL Teaching: Where Do We Stand? Procedia Social and Behavioral Sciences, 46, 5687-5692. http://dx.doi.org/10.1016/j.sbspro.2012.06.498

Nord, C. (2001). Translating as a Purposeful Activity - Functional Approaches Explained. Shanghai: Shanghai Foreign Language Education Press.

Pallant, J. (2013). SPSS Survival Manual: A Step by Step Guide to Data Analysis Using SPSS Program (5th ed.). Australia: Allen \& Unwin.

Paniagua, C. F. (2000). English-Spanish Translation, Through a Cross-Cultural Interpretation Approach. New York: UniversityPress of America.

Rafieyan, V., Norazman, A. M., \& Lin, S. E. (2013a). Relationship between Attitude toward Target Language Culture Instruction and Pragmatic Comprehension Development. English Language Teaching, 6(8), 125-132. http://dx.doi.org/10.5539/elt.v6n8p125

Rafieyan, V., Lin, S. E., \& Abdul-Rashid, M. (2013b). Language Learners' Attitudes towards the Incorporation of Target Language Culture into Foreign Language Instructions. International Journal of Linguistics, 5(4), 169-177. http://dx.doi.org/10.5296/ijl.v5i4.4193

Rafieyan, V., Sharafi-Nejad, M., Khavari, Z., Lin, S. E., \& Abdul-Rashid, M. (2014). Pragmatic Comprehension Development through Telecollaboration. English Language Teaching, 7(2), 11-19. http://dx.doi.org/10.5539/elt.v7n2p11

Rafieyan, V., Rafieyan, A., Rafieyan, N., Rafieyan, S., Rafieyan, P., Rafieyan, M. (2015). Effect of Developing Pragmatic Competence through Telecollaboration on Improving English as Foreign Language Learners' Writing Proficiency. Journal of Education and Practice, 6(27), 121-131.

Rafieyan, V. (in press a). Effect of 'Focus on Form' versus 'Focus on Forms' Cultural Instruction on Translation of Culture-Bound Texts.

Rafieyan, V. (in press b). Effect of Cultural Distance on Translation of Culture-Bound Texts. 
Rafieyan, V. (in press c). Relationship between Cultural Intelligence and Translation of Culture-Bound Texts.

Saldanha, G., \& O’Brien, S. (2014). Research Methodologies in Translation Studies. New Tork, NY: Routledge.

Toury, G. (1995).Descriptive Translation Studies and Beyond. Amsterdam: John Benjamins. http://dx.doi.org/10.1075/btl.4

Thuy, P. T. (2013). House's Functional-Pragmatic Model of Translation Assessment and Implications for Evaluating English-Vietnamese Translation Quality. VNU Journal of Foreign Studies, 29(1), 56-64.

Vyatkina, N., \& Belz, J. A. (2006). A Corpus-Driven Intervention for the Development of L2 Pragmatic Competence. In K. Bardovi-Harlig, J. C. Felix-Brasdefer, \& A. Omar (Eds.), Pragmatics and Language Learning (pp. 315-357). Honolulu: National Foreign Language Resource Center, University of Hawaii.

Yang, W. (2010). Brief Study on Domestication and Foreignization in Translation. Journal of Language Teaching and Research, 1(1), 77-80. http://dx.doi.org/10.4304/j1tr.1.1.77-80 